\title{
Anesthetic Approach in a Child with Laryngocele: A Case Study
}

\author{
Afsaneh Sadeghi, ${ }^{1}$ and Elham Memary ${ }^{2,3,{ }^{*}}$ \\ ${ }^{1}$ Anesthesiology Department, Mofid Hospital, Shahid Beheshti University of Medical Sciences, Tehran, Iran \\ ${ }^{2}$ Anesthesiology Department, Imam Hosein Hospital, Shahid Beheshti University of Medical Sciences, Tehran, Iran \\ ${ }^{3}$ Anesthesiology Research Center, Shahid Beheshti University of Medical Sciences, Tehran, Iran \\ "Corresponding author: Elham Memary, Anesthesiology Department, Imam Hosein Hospital, Shahid Madani St, Tehran, Iran. Tel: +98-9123870850, E-mail: \\ drmemary@gmail.com
}

Received 2017 February 01; Revised 2017 February 07; Accepted 2017 February 10.

\begin{abstract}
Introduction: Herein, we report our findings of the anesthetic management of a case of laryngocele to discuss the repercussions, which need to be considered in laryngocele management, and to determine the possible pressure effects on the airway.

Case Presentation: The patient was a 17-month-old girl with laryngocele, who was a candidate for surgery. Her symptoms had initiated with wheezing and occasional dysphagia. On bronchoscopy, a tracheal mass was observed, accompanied by stenosis and tracheal deviation to the right side of the neck. The patient underwent anesthesia with sevoflurane via spontaneous breathing. Anesthesia was maintained with an intravenous infusion of propofol to keep spontaneous breathing. The mass was removed by a surgeon, and after ensuring the safety of the airway, atracurium and morphine were injected intravenously. At the end of the operation, she was transferred to the pediatric intensive care unit under intubation.

Conclusions: Maintenance of spontaneous ventilation during anesthesia induction is crucial in cases of laryngocele at very young age.

Keywords: Anesthesiology, Laryngocele, Neck, Sevoflurane, Neuromuscular Blocking Agents, Airway Management
\end{abstract}

\section{Introduction}

Laryngocele is an abnormal benign cystic dilation, originating from laryngeal saccules filled up with air, mucus, or pus. This condition was first described in 1829 by a Napoleon army surgeon, Dominique Jean Larrey (1-3). As a very rare clinical condition, its incidence is reported to be about 1 per 2.5 million population per year and is reported more frequently among men $(4,5)$. It may be either acquired or congenital and can occur at any age; however, it is most commonly detected in the age range of $50-60$ years (5).

Laryngocele is mostly unilateral, although bilateral presentations have been also reported. It is categorized as internal, external, or combined (6) and usually presents as an asymptomatic cervical mass. Nevertheless, it may sometimes cause hoarseness, snoring, dysphonia, stridor, coughing, sore throat, shortness of breath, airway obstruction, and difficulty in swallowing $(1,7)$.

Symptomatic patients need to undergo surgery. Apparently, compromised airway and mass effects on the airway are possible in laryngocele; therefore, selection of the anesthetic approach could be a dilemma for surgeons (8-10). Herein, we report our findings of the anesthetic manage- ment of a case of laryngocele to discuss the repercussions, which need to be considered in laryngocele management, and to determine the possible pressure effects on the airway.

\section{Case Presentation}

The patient was a 17-month-old girl with a diagnosis of laryngocele in the left lateral region of the neck, who was a candidate for surgery. Her symptoms had started at 5 months of age with a wheezing sound in the chest and occasional dysphagia to solids. She had received outpatient treatment due to a probable diagnosis of asthma and was repeatedly hospitalized. Nonetheless, her condition had not improved, and diagnostic bronchoscopy was carried out. On bronchoscopy, a tracheal mass was detected, accompanied by stenosis and tracheal deviation to the right side of the neck.

In an overview, there was a swelling in the left lateral side of the neck at the level of hyoid bone anterior to the sternocleidomastoid muscle (Figure 1). In auscultation, the lungs were clear, but stridor of the main airway was evident during exhalation. Other examinations indicated no pathological findings. In the operating room, cardiac 
monitoring and pulse oximetry were applied, and the patient underwent anesthesia with sevoflurane via spontaneous breathing. After about 10 minutes of inhaling the gas and ensuring the appropriate depth of anesthesia, 20 mg of intravenous lidocaine was injected, and the patient was intubated with an endotracheal tube (No. 5) without a cuff under direct laryngoscopy. Correct tube placement was confirmed via continuous waveform capnography.

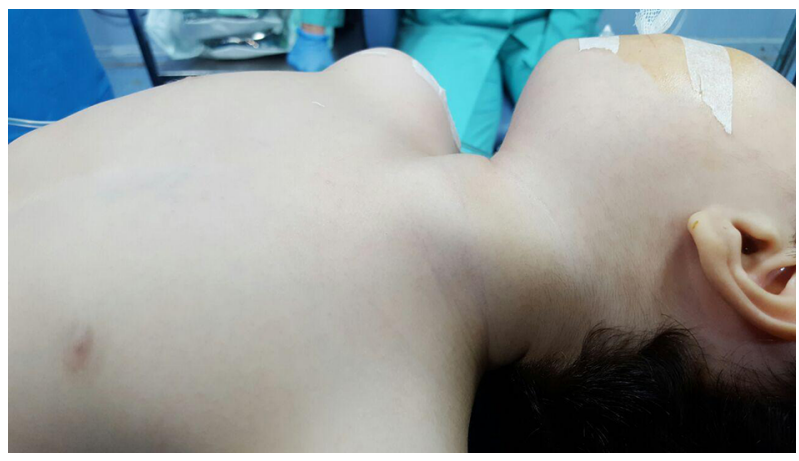

Figure 1. Swelling of the Left Lateral Side of the Neck

Anesthesia was maintained with an intravenous infusion of propofol at $100 \mu \mathrm{g} / \mathrm{kg} / \mathrm{min}$ while keeping spontaneous breathing. Before performing the surgical incision, $20 \mathrm{mg}$ of bupivacaine was infiltrated, and the mass was removed by the surgeon (Figure 2 ). At this point, after ensuring the safety of the airway, $5 \mathrm{mg}$ of atracurium and $1 \mathrm{mg}$ of morphine were intravenously injected. At the end of the operation, the child was transferred to the pediatric intensive care unit under intubation. She was extubated 5 days later and was finally discharged from the hospital in a good general condition.

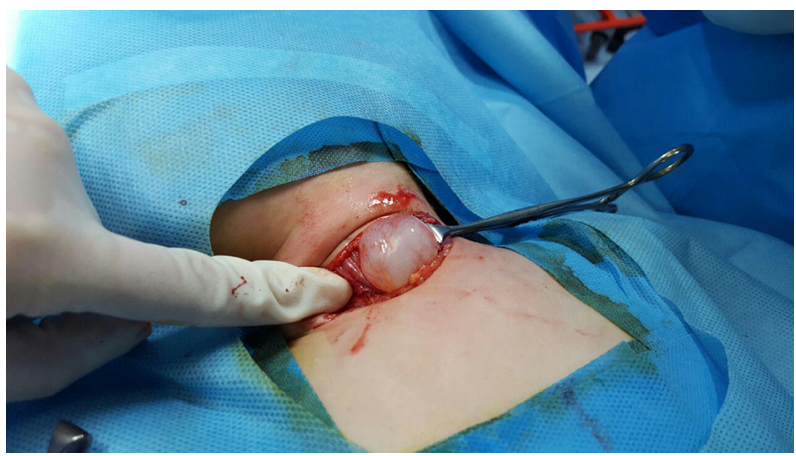

Figure 2. The Laryngocele After Performing Surgical Incision

\section{Discussion}

Regardless of the surgical approach, which may be excision with an external approach, microlaryngoscopy with $\mathrm{CO}_{2}$ laser, or advanced robotic surgery, anesthesia is still an important part of laryngocele management (11). Selection of an anesthetic technique in patients with laryngocele can be a source of concern. The proper anesthetic approach should be determined via preoperative assessment and early preparation (12). Careful history-taking and physical examination before any intervention are also essential. Moreover, review of patients' medical records and radiological imaging are strongly recommended.

Apparent anatomical features, signs and symptoms, and visualized mass markers, which can have direct effects on subsequent airway plans, should be identified. Such findings can inform the anesthesiologist about the potential difficulties of intubation and ventilation, especially after the administration of neuromuscular blocking agents (13). Besides all preoperative anticipations of a difficult airway, all related modalities and unexpected events should be prepared and predicted, respectively.

The approach to a difficult airway is selective, although preparation of equipments, assistants, expertise, and environment are always important. It is recommended that a skilled anesthesiologist in fiberoptic intubation be accessible. In life-threatening conditions, some other invasive measures, such as cricothyrotomy or tracheostomy, may be required for maintaining proper oxygenation and ventilation (12-14). Surgical cricothyrotomy at young age is not allowed, although needle cricothyrotomy can be safely performed (15).

Airway management in cases of laryngocele frequently includes awake options, such as fibreoptic intubation and the classic tracheostomy under local anesthesia to preserve a patent airway (16-18). Awake options are also not applicable at very young age. Therefore, in our case, the expert anesthesiologist insisted on avoiding neuromuscular blocking agents during intubation and used sevoflurane with the aim of preserving the patient's ventilation.

Sevoflurane is an ether inhalation anesthetic agent with a pleasant odor. It has a rapid onset of action, acceptable recovery characteristics, and few cardiovascular side effects. Its low solubility enables accurate control over the depth of anesthesia. Overall, it is an acceptable induction agent for controlling apprehension and fear in pediatric patients. Accordingly, it is a proper option for the induction and maintenance of anesthesia in ambulatory and nonambulatory surgeries in pediatrics $(19,20)$.

Under rare circumstances, if urgent airway management is required in a patient with laryngocele, ultrasoundguided transcutaneous needle aspiration can be applied 
(17). Postoperative complications are rare following successful anesthesia and careful surgical approach; also, extubation is expected to be less eventful than intubation (12, $14)$.

\section{Acknowledgments}

We would like to thank all the staff of the operating room of Mofid hospital, who assisted us in the management of this patient.

\section{Footnotes}

Authors' Contribution: All authors met the criteria for authorship contribution, based on the recommendations of the international committee of Medical journal editors.

Financial Disclosure: None.

Funding/Support: None.

\section{References}

1. Suqati AA, Alherabi AZ, Marglani OA, Alaidarous TO. Bilateral combined laryngocele. Saudi Med J. 2016;37(8):902-3. doi: 10.15537/smj.2016.8.15104. [PubMed: 27464869].

2. Pallagatti S, Sheikh S, Aggarwal A, Singh R, Goyal G, Bansal N. Laryngocele: A Case Report. Asian J Oral Health Allied Sci. 2012;2(1):63-5.

3. Gupta R, Gupta S, Bhat A, Kalsotra P, Singh KP, Prakash O, et al. Bilateral Mixed Laryngocele. Int J Phonosurg Laryngol. 2013;3:69-72. doi: 10.5005/jp-journals-10023-1067.

4. Vasileiadis I, Kapetanakis S, Petousis A, Stavrianaki A, Fiska A, Karakostas E. Internal laryngopyocele as a cause of acute airway obstruction: an extremely rare case and review of the literature. Acto Otorhinolaryngol Ital. 2012;32(1):58-62. [PubMed: 22500070].

5. Swain SK, Chandra Mallik K, Mishra S, Chandra Sahu M. Laryngocele: Experience at a Tertiary Care Hospital of Eastern India. Voice. 2015;29(4):512-6. doi: 10.1016/j.jvoice.2014.09.013. [PubMed: 25704473].
6. Prasad KC, Vijayalakshmi S, Prasad SC. Laryngoceles - presentations and management. Indian J Otolaryngol Head Neck Surg. 2008;60(4):303-8. doi: 10.1007/s12070-008-0108-8. [PubMed: 23120570].

7. George I, Hasan S, Kumar GN, Tobook SM, Dhinakar M. A rare case of laryngocele in a young Omani male. Oman Med J. 2010;25(2).

8. Felix JA, Felix F, Mello LF. Laryngocele: a cause of upper airway obstruction. Braz J Otorhinolaryngol. 2008;74(1):143-6. [PubMed: 18392516].

9. Fredrickson KL, D’Angelo AJ. Internal laryngopyocele presenting as acute airway obstruction. Ear Nose Throat J. 2007;86(2):104-6. [PubMed: 17385620].

10. Pennings RJ, van den Hoogen FJ, Marres HA. Giant laryngoceles: a cause of upper airway obstruction. Eur Arch Otorhinolaryngol. 2001;258(3):137-40. doi: 10.1007/s004050100316. [PubMed: 11374255].

11. Zelenik K, Stanikova L, Smatanova K, Cerny M, Kominek P. Treatment of Laryngoceles: what is the progress over the last two decades? Biomed Res Int. 2014;2014:819453. doi: 10.1155/2014/819453. [PubMed: 24729979].

12. Aidonis I, Skalimis A, Kirodimos E. Surgical and anesthetic considerations of laryngeal saccular cyst: a case report. J Med Case Rep. 2011;5:283. doi: 10.1186/1752-1947-5-283. [PubMed: 21729258].

13. Baker PA, Navaratnarajah J, Black AE. Assessment and management of the predicted difficult airway in babies and children. Anaesth Intensive Care Med. 2015;16(12):622-31. doi:10.1016/j.mpaic.2015.09.002.

14. Thabet MH, Kotob H. Lateral saccular cysts of the larynx. Aetiology, diagnosis and management. J Laryngol Otol. 2001;115(4):293-7. doi: 10.1258/0022215011907488. [PubMed: 11276332].

15. Scrase I, Woollard M. Needle vs surgical cricothyroidotomy: a short cut to effective ventilation. Anaesthesia. 2006;61(10):962-74. doi: 10.1111/j.1365-2044.2006.04755.x. [PubMed: 16978312].

16. Leong CL, Badran K, McCormick MS. Laryngocoele presenting as acute airway obstruction. Singapore Med J. 2007;48(3):e84-6. [PubMed: 17342278].

17. Mace AT, Ravichandran S, Dewar G, Picozzi GL. Laryngopyocoele: simple management of an acute airway crisis. J Laryngol Otol. 2009;123(2):248-9. doi: 10.1017/S0022215108002417. [PubMed: 18439335].

18. J PR. Gigant laryngocele airway management scrotal mass. Imag J Clin Med Sci. 2014;1(2):18-9. doi:10.17352/2455-8702.000012.

19. Goa KL, Noble S, Spencer CM. Sevoflurane in paediatric anaesthesia: a review. Paediatr Drugs. 1999;1(2):127-53. doi: 10.2165/00128072199901020-00005. [PubMed: 10937447].

20. Lee M, Bennett HE, Gordon N. Sevoflurane general anesthesia: an alternative technique in the pediatric oral and maxillofacial surgery patient. J Oral Maxillofac Surg. 2003;61(11):1249-52. doi: 10.1016/S02782391(03)00723-7. [PubMed: 14613078]. 